\title{
The Future We Want: A Learning Experience to Promote SDGs in Higher Education from the United Nations and University of Valencia
}

\author{
Victoria Vázquez-Verdera ${ }^{1, *(\mathbb{D})}$, Juan Domingo ${ }^{2}(\mathbb{D})$, Esther Dura ${ }^{2} \mathbb{D}$, Daniel Gabaldón-Estevan ${ }^{3}(\mathbb{D}$, \\ Ernesto López-Baeza ${ }^{4}$ (D) , Sonia Machause López ${ }^{5}$ (D) Fabiola Meco-Tébar ${ }^{6}$ (D) Silvia Rueda ${ }^{2}$, \\ José Javier Serrano-Lara ${ }^{7}$ (D), Isabel Signes-Soler ${ }^{8}$ (D), María Luisa Vázquez de Ágredos Pascual ${ }^{9}$ (D) \\ and Elena Martínez-García ${ }^{10}$ (D)
}

Citation: Vázquez-Verdera, V.;

Domingo, J.; Dura, E.;

Gabaldón-Estevan, D.; López-Baeza,

E.; Machause López, S.; Meco-Tébar,

F.; Rueda, S.; Serrano-Lara, J.J.;

Signes-Soler, I.; et al. The Future We

Want: A Learning Experience to

Promote SDGs in Higher Education

from the United Nations and

University of Valencia. Sustainability

2021, 13, 8550. https://doi.org/

$10.3390 /$ su13158550

Academic Editor:

Francisco Zamora-Polo

Received: 30 June 2021

Accepted: 27 July 2021

Published: 31 July 2021

Publisher's Note: MDPI stays neutral with regard to jurisdictional claims in published maps and institutional affiliations.

Copyright: (C) 2021 by the authors. Licensee MDPI, Basel, Switzerland. This article is an open access article distributed under the terms and conditions of the Creative Commons Attribution (CC BY) license (https:/ / creativecommons.org/licenses/by/ $4.0 /)$
1 Departmento de Teoría de la Educación, Facultad de Filosofía y Ciencias de la Educación, Universitat de València, 46010 València, Spain

2 Department de Informática, Escuela Técnica Superior de Ingeniería, Universitat de València, 46100 Burjassot, Spain; Juan.Domingo@uv.es (J.D.); Esther.Dura@uv.es (E.D.); Silvia.Rueda@uv.es (S.R.)

3 Departamento de Sociología y Antropología Social, Facultad de Ciencias Sociales, Universitat de València, 46021 Valencia, Spain; Daniel.Gabaldon@uv.es

4 Departamento de Física de la Tierra y Termodinámica, Facultad de Física, Universitat de València, 46100 Burjassot, Spain; Ernesto.Lopez@uv.es

5 Departamento de Prehistoria, Arqueología e Historia Antigua, Facultad de Geografía e Historia, Universitat de València, 46010 Valencia, Spain; Sonia.Machause@uv.es

6 Departamento de Derecho Civil, Facultad de Derecho, Universitat de València, 46022 Valencia, Spain; Fabiola.Meco@uv.es

7 Departamento de Geografía, Facultad de Geografía e Historia, Universitat de València, 46010 Valencia, Spain J.Javier.Serrano@uv.es

8 Departamento de Óptica y Optometría y Ciencias de la Visión, Facultad de Física, Universitat de València, 46100 Burjassot, Spain; Isabel.Signes@uv.es

9 Departamento de Historia del Arte, Facultad de Geografía e Historia, Universitat de València, 46010 Valencia, Spain; M.Luisa.Vazquez@uv.es

10 Departamento de Derecho Administrativo y Procesal, Facultad de Derecho, Universitat de València, 46022 Valencia, Spain; Elena.Martinez@uv.es

* Correspondence: Toya.Vazquez@uv.es; Tel.: +34-96-3864672

Abstract: This article shares the strategy for mainstreaming the Sustainable Development Goals (SDGs) at the University of Valencia (UV), which, although limited in its scale, may compel other Higher Education Institutions to think in technological and social progress aligned with the 2030 Agenda. It explicates a process driven by the UV, on the occasion of the 75th anniversary of the United Nations (UN), and in collaboration with the Service for Geospatial, Information, and Telecommunications Technologies from the UN Support Base in Valencia (Spain) to prepare the online event: "The United Nations We Want". It was the culmination of a collaborative project between students and faculties from different scientific, technological, social, legal, humanistic, and health disciplines that structure the University of Valencia. The intention was that new generations experience the role they can have to shape the future we want, while the university community as a whole can become part of transformative institutional change that draws on both top-down and bottom-up strategies in pursuit of Education for Sustainable Development.

Keywords: education for sustainability; artificial intelligence; cross-cutting competencies; interdisciplinary dialogue; sustainable development goals

\section{Introduction \\ General Introduction about the Role Universities Can Play in the 2030 Agenda}

Current circumstances may overload us with messages and emergencies, but it is vital to question our planetary-shared situation. The enormous flows of data being handled in the twenty-first century pose a question that is especially relevant: 
"The world is changing faster than ever before, and we are flooded by impossible amounts of data, of ideas, of promises, and of threats. Humans relinquish authority to the free market, to crowd wisdom, and to external algorithms partly because they cannot deal with the deluge of data. In the past, censorship worked by blocking the flow of information. In the twenty-first century, censorship works by flooding people with irrelevant information. People just do not know what to pay attention to, and they often spend their time investigating and debating side issues. In ancient times, having power meant having access to data. Today, having power means knowing what to ignore. Thus, considering everything that is happening in our chaotic world, what should we focus on?" ([1], p. 430).

In terms of transforming educational policies and practices, we consider the need to rethink what we produce from the criterion of social value. Artificial Intelligence and the huge amount of data that it mobilizes have starkly shown how vulnerable we are on the ways of interacting at private and public spaces, food supply systems, workshops, and other spaces, like the educational ones. Part of the challenge ahead of us is to understand the need for prudent management of our own vulnerability and activation of innovative social, corporate, labour, fiscal, and economic models. Moreover, public deliberation is not always listened to for identifying social priorities and articulating policy priorities. We need to open the debate because, following Harari's arguments, "Despite all the talk of pollution, global warming, and climate change, most countries have yet to make any serious economic or political sacrifices to improve the situation. When the moment comes to choose between economic growth and ecological stability, politicians, CEOs, and voters almost always prefer growth. In the twenty-first century, we shall have to do better if we are to avoid catastrophe" ([1], p. 31).

Nowadays, universities are expected to work within the Sustainable Development Goals (SDGs) framework [2]. The 2030 Agenda can be the object of dialogue and reflection on what transformative education should look like so as to carefully design a global monitoring framework [3]. Drawing on the literature and case study experiences implementing education for SDGs, we decided to integrate strategies for creating learning spaces [4-9]. This paper explores how the University of Valencia (UV), on the occasion of the 75th anniversary of the United Nations (UN), and in collaboration with the Service for Geospatial, Information and Telecommunications Technologies from the UN Support Base in Valencia, has prepared the online event: "The United Nations We Want" (https:/ / www.uv.es/uvweb/college/en/university-events/united-nations-wewant-1285851282125/Esdeveniment.html?id=1286186806266, accessed on 28 July 2021). It was the culmination of a collaborative process between students and faculties from different scientific, technological, social, legal, human, and health disciplines that structure the University of Valencia (Spain). All of them were reflecting together to address the challenges of Artificial Intelligence (AI) societies and technologies to drive transformations aligned with the 2030 Agenda. That process was not done by each knowledge discipline as reported in other studies [10-12], but from an interdisciplinary dialogue [13]. This article will not describe an evaluation of the online event, but, rather, explains the process driven with the intention to develop internal and external networks that will engage the university in interdisciplinary dialogue in order to work towards transformative frameworks to address Education for Sustainability.

The process has been driven with the intention that new generations experience the role they have to shape the future we want. For those reasons, we developed an array of educational resources that try to respond to the concerns of anyone who wants to contribute to social change also from his/her university role. The aim of more sustainable realities to come needs university collaborations with other social agents. Engaging people and institutions as change agents needs to create connections with external stakeholders and a transformative pedagogy inside the institution.

The analysis discussed in the dialogic process was fed from feminist and decolonizing frameworks [14-16] and from a global economic slowdown [17]. We need to allow 
awareness of the desire to learn, to reflect and explore something that affects us and the future of our students on our fragile planet. For that reason, the participation of internal and external agents was paramount (see Figure 1):

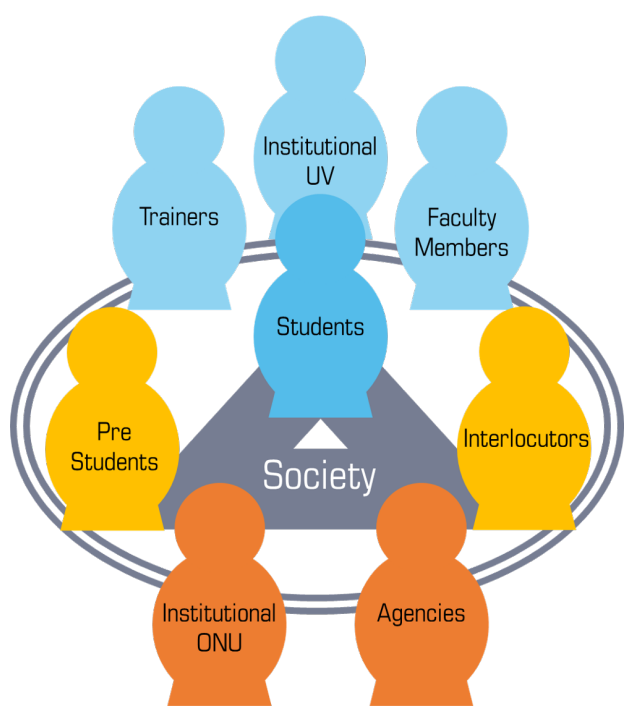

Figure 1. Internal and external agents involved in the process. Source: own elaboration.

The date chosen for the celebration of the public debate between UN representatives and UV students was 22 April 2021, International Earth Day, in order to remember the need to protect biodiversity and care for our shared home: Earth. The event was opened by the Director of the United Nations Global Service Center; the Rector of Universitat de València; and the President of the Generalitat Valenciana (regional government). As United Nations interlocutors, we counted on the participation of the Director for Innovation, Education, and Investment of UNWTO; the UPOV Legal Counsel and Director of Training and Assistance; the 75th Anniversary Coordinator for Spain (and former Director of FAO in Spain); and the Director of the ILO Office for Spain and Expert on the 2030 Agenda. The next generations participated in the closing ceremony. Two 12-year-old children exposed their desires to the UN.

In this way, the participation of the different agents from inside and outside the University facilitated conversations, mutual learning, and partnerships between different sectors. On an internal level, it helped to identify areas of shared interest across the UV and opportunities for internal collaboration. It made the engagement of faculty members and students to build capacity in the SDG framework possible. However, it also had an external impact in two dimensions, namely i. partnerships with United Nations agents to connect and work together on shared interests in future; and ii. engagement of a broad audience. The online event on 22 April was followed by nearly 160 nodes, including mass media agents, civil society entities, schools, and all-aged citizens in general.

Universities can help drive technological and societal progress that take into account the 2030 Agenda. In fact, not only can it, but also the university context must become one of the actors that favor and guarantee the well-being of the planet and people, precisely because of the important role that future generations will play in this process. The dialogue between all internal and external agents is critical for helping the local and global community understand the AI's challenges, opportunities, and interactions between the SDGs. Working with common horizons would facilitate to develop and implement sensitive responses, compromise with public policy, and open transformation pathways.

\section{The UN That We Want}

\subsection{Background and Motivation}

The 2030 Agenda was the compass to open a debate that allowed us to reflect on the positive and negative impacts of AI. The full title of the 2030 Agenda is "Transforming Our 
World: The 2030 Agenda for Sustainable Development." Consequently, by responding to university community ideas and proposals, participants were allowed to open questions and enrich their own knowledge. It allowed people to imagine how AI can or cannot progress toward a new social contract, sustainable, responsible models of production and consumption, and peaceful, just, egalitarian societies.

The methodologies activated for students and faculty members participation were in accordance with the principles established in Education for SDG, Learning Objectives (2017). Education for Sustainable Development (ESD) facilitates significant drivers for changes in curriculum topics and methodologies. In addition, indeed, increases student demand for a sustainability-centered education:

"Subject disciplines, subject didactics, educational sciences and practice-oriented studies should include methodology principles and subject knowledge from ESD. Learning on the basis of real societal challenges in local contexts requires cooperation with external partners. Modules should thus enable access to external partners" ([18], pp. 51-52).

The activities generated for the realization of the event "The United Nations We Want" gave the University opportunities to form new collaborations with government, social agents, and the community in both research and education. Addressing the challenges of AI societies and technologies requires new ways of doing things, hard choices between competing options, and in some cases profound transformations. Four Discussion Panels were formed in order to address the challenges and impacts of AI in people and the planet from interdisciplinary approaches.

The three dimensions of sustainability were also attended in each of the four Discussion Panels: social, economic, and environmental transitions needed for AI to facilitate a sustainable development were studied. The challenges to avoid negative impacts on the planet and people were identified as obstacles to achieve specific SDGs. All SDGs must be viewed in a holistic approach and act as a road map to orientate transformations in economic, social, and environmental issues. The future in our shared planet requires critical thinking, constructing common horizons and working in alliance with others. The AI debate was articulated in four Discussion Panels with specific SDGs assigned to each one (see Table 1).

The learning process started with the synchronous tutorial about "the cross-cutting key competencies for achieving all SDGs and Artificial Intelligence". It was designed for faculty members, but some students also attended. It had a duration of two hours and was held on 17 December 2020 as a first approach to the contents that could be addressed in the Discussion Panels. During the afternoon session, which was recorded in order to be available for people who could not attend, the University community responded to the offered guide-questions and proposed their own, which were accepted to create new proposals.

The second tutorial was open for faculty members and students of all areas of knowledge: "Basic training on AI. Glossary of key concepts and presence of AI in today's reality". It had a duration of one hour and was available on Moodle from January 2021. The last and third tutorial was "Can machines think? The current limits of artificial intelligence". It also had a duration of one hour and was available on Moodle from January 2021.

Later, there were four synchronous workshops guided from the UN Depository Library-which it hosted at the university (ONUBIB) - to help people from each of the four Panels to find specific documentation. An array of specific reports were available for the whole community: students and faculty members. In the workshops, they also learned how to use the library tools, by inviting them to go far away from the standpoint offered. An average of 20-30 people (including teachers and students) participated in each of the four workshops. Active and respectful participation was energized, which helped to collect very interesting reflections and action proposals. Workshops had a duration of one hour each and were held on 1-4 February 2021 during afternoon sessions. 
Table 1. Table panels. Discussion Panels, SDGs, and their impacts.

\begin{tabular}{|c|c|c|c|c|}
\hline & \multicolumn{4}{|c|}{ Discussion panels and SDGs } \\
\hline Impacts & $\begin{array}{l}\text { Science and } \\
\text { technology for } \\
\text { the fulfilling of } \\
\text { SDGs and the } \\
\text { mitigation of } \\
\text { climatic change }\end{array}$ & $\begin{array}{c}\text { Artificial } \\
\text { Intelligence in a } \\
\text { finite planet: } \\
\text { challenges posed } \\
\text { by the } 2030 \\
\text { Agenda }\end{array}$ & $\begin{array}{l}\text { Opportunities } \\
\text { and challenges } \\
\text { of Education for } \\
\text { Sustainable } \\
\text { Development; } \\
\text { the digital era } \\
\text { from the ethic, } \\
\text { historical and } \\
\text { anthropological } \\
\text { perspective }\end{array}$ & $\begin{array}{c}\text { Human rights } \\
\text { and Artificial } \\
\text { Intelligence at } \\
\text { the service of } \\
\text { the } 2030 \\
\text { Agenda. }\end{array}$ \\
\hline $\begin{array}{c}\text { Transformation } \\
\text { with economic } \\
\text { impact }\end{array}$ & $\begin{array}{l}\text { Interactions with } \\
\text { the rest SDGs }\end{array}$ & $\begin{array}{c}\text { SDGs: } 8,9 \text { and } \\
12\end{array}$ & SDGs: 1 and 2 & SDG: 3 \\
\hline $\begin{array}{c}\text { Transformation } \\
\text { with social } \\
\text { impact }\end{array}$ & SDG: 11 & SDG 10 & SDGs: 4 and 17 & $\begin{array}{c}\text { SDGs: } 4,5 \text { and } \\
16\end{array}$ \\
\hline $\begin{array}{l}\text { Transformation } \\
\text { with environ- } \\
\text { mental impact }\end{array}$ & $\begin{array}{l}\text { SDGs: } 6,13,14 \\
\text { and } 15\end{array}$ & SDG: 7 & $\begin{array}{l}\text { Interactions with } \\
\text { the rest SDGs }\end{array}$ & $\begin{array}{l}\text { Interactions } \\
\text { with the rest } \\
\text { SDGs }\end{array}$ \\
\hline
\end{tabular}

In a different phase of the project, public speaking workshops were held. Ideas and proposals were collected and given the form to generate stimulating speeches. In order to clarify the elements of quality speakers, there were some synchronous sessions dedicated to theoretical knowledge. In addition, other on-site practical sessions to practice strategies and make proposals which were analyzed. These practical workshops were held in very small groups and were face-to-face. The public speaking workshops added a total duration of thirty-two hours.

\subsection{Artificial Intelligence as a Pivotal Topic}

As it has been described in Section 1, the learning experience described in this paper arises from the collaboration of two partners: United Nations and the University of Valencia, with the aim of spreading the knowledge and adherence to SDGs by the University community, and particularly the students. Nevertheless, instead of approaching the topic from a totally general perspective, it was decided that AI would be taken as the pivotal topic, focusing on those features in which AI can contribute to SDGs' adoption but also noticing the potentially negative impact it may have on them. Focusing the work on a specific object of debate, such as artificial intelligence, allowed the areas of engineering and experimental sciences to feel challenged to contribute with their knowledge to an interdisciplinary reflection on sustainability issues

This decision was undoubtedly motivated by the recent emergence of AI (or to be precise, of a part of it: big data analysis) as a ubiquitous tool for improving (or at least, changing) the way in which many daily processes are performed. This involves critical tasks like energy production, distribution and consumption, management of transportation, either of goods or of people, climate change assessment, and many others. However, there are also more mundane activities like spreading of information or disinformation in social networks or person-to-person contacts for selling or interchanging goods or services. One of the biggest challenges for the organizers of this learning experience has been to explain to non-technical people, in understandable terms, what AI is and how and in which way it is changing our lives. Only in this way can students and faculty members from many fields elaborate an informed and critical personal and collective position about the influence of AI on the SDGs. 
An organization that can accomplish this goal, and that we could call transversal diffusion of AI, required the presence of experts in different areas in each of the work groups so that those aspects of AI that are more relevant to the topic of the group can be understood, but, also, by listening experts in the topic. AI experts can reflect on how their methods and tools should really be used in an ethical manner and how they can contribute to sustainability. This organization was implemented as four Discussion Panels (see Section 3.1), namely:

- Science and technology for the fulfilling of SDG's and the mitigation of climatic change.

- Artificial Intelligence in a finite planet: challenges posed by the 2030 Agenda.

- Opportunities and challenges of Education of Sustainable Development: the digital era from the ethic, historical, and anthropological perspectives.

- Human rights and Artificial Intelligence at the service of the 2030 Agenda.

As a practical action, seminars with a non technical but rigorous introduction to AI, as long as debates and other activities, were performed. Detailed description of all of them can be found in Section 3 (more concretely, in Section 3.1). From now on, we only highlight the general introduction to AI in the form of a conference that was also recorded for later consultation. Its main goal was to clarify the concept of AI, its evolution, and how it is currently used in a restricted version in most of the aforementioned applications.

Originally, and, according to its name, AI was conceived as a way to get a really intelligent system (indistinguishable from a human mind) by artificial, mainly computational, means. For this and other possible definitions of AI, see [19]. This is the most extreme position, named thereof as "hard" or "strong AI". That goal has not been reached, and it is doubtful if it is even possible. However, there is a less extreme position: the one proposed by those who see AI as the fact of getting a computer to do anything that, in the case of being done by humans, would be called intelligent. The so-called "weak AI" (the type of AI that operates on limited knowledge domains) is covered by this definition and, despite its inherent limitations since it explicitly renounces to create a fully functional human-like mind, it has been, and it is currently a great success. Programs that play chess or go that can answer some questions posed to them in natural language (digital assistants) or that help doctors in diagnosis from medical images are commonplace now.

Underlying all of these examples of success is a part of AI called Machine Learning (ML). Essentially, ML is aimed at learning from examples, i.e., the program operates with an algorithm (or a family of them) tuned by parameters whose values can change to adapt to many different problems. The adaptation is done by the ML system based on a wide sample of examples of different instances of the problem: those which solve it well, but also others which do it poorly and even which do not do it at all. An excellent text is [20]. The prevalent method for ML nowadays is called deep learning (DL), a computationally intensive but usually very effective method that finds the parameters of computational neurons, which are artificial units of computation that are said to imitate to some extent the behavior of human neurons and their connections. The interested reader may find more information in [21].

In any case, it is important to remember that ML, and DL in particular, requires a massive amount of data to be trained. Data are so important that their collection, curation, and storage, as well as the algorithms to extract knowledge from them, constitute a new field of engineering called Big Data. The use of such amounts of data brings some technical problems connected with the misuse of resources, mainly energy and network bandwidth, but, overall, ethical and legal problems related with privacy, misinformation, and mass media manipulation.

A problem that the faculty members involved in this collaborative project found is how to teach these and other related concepts like sensorization, data processing, cloud computing, etc. to a non-technical audience. Working with examples, and trying to generalize from them, seems to have been a sensible approach. Some interesting suggestions, including the use of serious games, are reviewed in [22]. 
According to the previous considerations, the features of AI and/or Big Data mostly related with SDGs and, consequently, those which were more emphasized are sensorization (which types of data can be collected), processing (which algorithms can and should be used), and accessibility (public availability and assurance of integrity of collected data).

The former points were developed, either as seminars or as Discussion Panels with the participation of faculty members, who first took the main responsibility for introducing the topic technically, but participation of alumni was encouraged, as long as the different activities were done.

\subsection{Contents and Objectives: Artificial Intelligence and Transversal Competencies for Curricular Sustainability}

Connecting Artificial Intelligence (AI) to different disciplines of the University was based on the transversal characteristics of the joining debate between UV students and the interlocutors designed by the UN. Disciplines as different as Physics, Law, Environment, Artificial Intelligence, etc. were intertwined within the same working group and the same Discussion Panel, in a real interdisciplinary exercise of great interest to our students, as well as the fact that, in itself, it materializes the need for alliances to walk towards the same horizon (SDG 17). Faculty members and students seemed all to be a bit skeptical at the beginning. However, there was the common objective of the interest in deepening the SDGs in everyone's life and at the UV. Everyone's motives could have been diverse, but, at the bottom, was the interest for a better planet. The focus of this collaborative project was then on what united everybody towards the common objective. The students relied on the faculty members and got engaged from the very beginning. The intention was to build something new together, totally different from conventional education, and sustain the uncertainty that was, at times, fairly intense. In reality, faculty members and students became project partners after the preliminary initial meetings. In addition, this is what gave this learning project one of its main characteristics as that of being highly innovative. Faculty members, together with students, with the uncertain goal of an open debate with UN officers, only a few months ahead, were preparing themselves and preparing unexpected allegations and possible responses, devising and reasoning how AI could help the Planet and People to Shape the Future Together. The only certainty was to contribute to the UN's interest of getting to know from students the role of AI in achieving the SDGs.

Ramos Torres [23], in the framework of the UNESCO International Institute for Higher Education in Latin America Latina and the Caribbean (IESALC UNESCO, from its acronym in Spanish (https: / / www.iesalc.unesco.org/, accessed on 28 July 2021), clearly expresses the role and the contribution of higher education to the SDGs from teaching. Higher education institutions generate and disseminate knowledge, and the SDGs themselves demand new knowledge and suggest future changes based on science. Moreover, SDG target 4.3, more explicitly identified with higher education, aims to, by 2030, ensure equal access for all women and men to affordable quality technical, vocational, and tertiary education, including university, which is being considered as one of the factors that will make it possible to achieve all the SDGs, due to the impacts that the SDGs have on higher education.

Undoubtedly, the joint debate between the UV students and the SGITT UNSB-V on Shaping Our Future Together-The United Nations We Want: Artificial Intelligence, Planet, and People has been an extraordinarily good opportunity for UV faculty members and students to delve into and show the significant role of transversal competencies in curriculum sustainability. It is clear that UV is not only actively pursuing sustainability, but it also shows a very significant series of achievements (activities, teaching, research, etc.) on this subject (See https:/ / www.uv.es/uv-sustainability/en/uv-sustainability.html, accessed on 28 July 2021). However, in order for faculty members to be prepared to facilitate Education for Sustainable Development, they must develop sustainability key competencies (including knowledge, skills, attitudes, values, motivation, and commitment). However, in addition to general sustainability competencies, they also need more specific competencies to facilitate faculty members' capacity to help people develop sustainability competencies 
through a range of innovative teaching and learning practices [24]. The university has a program on sustainability education and learning (See https:/ /www.uv.es/uv-sustainability / en/educacio-i-investigacio/educacio-i-aprenentatge/formacio-i-sensibilitzacio.html, accessed on 28 July 2021) and has a specific Working Group on Curricular Sustainability (See https:/ / www.uv.es/uvweb/nullen/education-research/gt4-sostenibilitat-curricular1286109114475.html, accessed on 28 July 2021).

Following UNESCO [18], competencies describe the specific attributes' individuals need for action and self-organization in various complex contexts and situations. They include cognitive, affective, volitional, and motivational elements; hence, they are an interplay of knowledge, capacities and skills, motives, and affective dispositions. Competencies cannot be taught but have to be developed by the learners themselves. They are acquired in action, on the basis of experience and reflection.

The preparation for the debate has provided a good opportunity to faculty members and students to put into practice key competencies that are considered crucial for the sustainable development, identifying learning objectives in totally new topics and approaches for the students that are significant for the 17 SDGs. These key competencies are considered transversal and multi-functional, given the specific characteristics of the four Discussion Panels. It follows below some of the activities and opportunities that have helped or contributed to achieving them. UNESCO competencies (as in [18]) are expressed in italics:

Systems thinking competency: the abilities to recognize and understand relationships; to analyze complex systems; to think of how systems are embedded within different domains and different scales; and to deal with uncertainty.

The students had to tackle, many of them for the first time,

- The complexity of the Climate System, interactions between its components and feedback processes at different spatial and temporal scales;

- The interactions of productions chains based on AI and its impacts on the planet and people;

- The financialization of the global economy and the complexity of insubstantial paper values that endanger the livelihoods of billions of people;

- Relationships in Planet Earth and the significance of human actions;

- The search for nature based solutions to many of the planet problems;

- Interest of applying Earth Observation remote sensing techniques for different indicators;

- Understanding and managing uncertainty as unavoidable risk-taking and risk-sharing also considering the cost of being reluctant to acting.

Anticipatory competency: the abilities to understand and evaluate multiple futures-possible, probable, and desirable - to create one's own visions for the future; to apply the precautionary principle; to assess the consequences of actions; and to deal with risks and changes.

- Analyzing past World Economic Forum global risks (economic, environmental, geopolitical, societal, and technological) forecasts seeing how they have evolved in the last few years, also considering the unforeseeable COVID-19 pandemic;

- Learn to anticipate unintended consequences, and to conceptualize, construct, and communicate the probable fundamental characteristics of the future;

- Anticipate the effect of AI on the different SDGs. Towards gaining more knowledge and predictive capacity;

- Learn the technique for building different scenarios: What would happen if ... ?

- Precautionary principle based on risk analysis, trusting science, balance between preventive actions and innovation;

- Again, consider the cost of inaction. 
Normative competency: the abilities to understand and reflect on the norms and values that underlie one's actions; and to negotiate sustainability values, principles, goals, and targets, in a context of conflicts of interests and trade-offs, uncertain knowledge, and contradictions.

- Ability to negotiate sustainability values, achieve country coalitions;

- Role of non-governmental and Intergovernmental Organizations;

- Ethical issues. Scope and limitations of AI;

- Significant role played by the Law lecturers in the team by establishing the ethics underlying the different $\mathrm{AI}$ algorithm applications, defending privacy and right to privacy.

Strategic competency: the abilities to collectively develop and implement innovative actions that further sustainability at the local level and further afield. Strategic thinking. What is required to achieve SDGs?

- Ability to connect AI (technology) to the social world. Capacity (readiness) of technology to evolve with time and facilitate adaptation to changes;

- Sustainable technology;

- Capacity to communicate sustainable concern for general public and neutralize fake news.

Collaboration competency: the abilities to learn from others; to understand and respect the needs, perspectives, and actions of others (empathy); to understand, relate to, and be sensitive to others (empathetic leadership); to deal with conflicts in a group; and to facilitate collaborative and participatory problem solving;

- Managing multidisciplinary teams;

- Teamwork capabilities, active listening, managing conflict, consensus building, etc.;

- Faculty members and students working together: faculty members showing different alternatives or providing knowledge but adapting themselves to the students' working dynamics, using their communication and virtual meeting tools, for example;

- Leadership attitudes and aptitudes;

- Define the role of the group representatives.

Critical thinking competency: the ability to question norms, practices, and opinions; to reflect one's values, perceptions, and actions; and to take a position in the sustainability discourse.

- Absolutely needed when the amount of information is massive;

- Ability for analysis, synthesis, problem identification and problem solution, evaluation;

- To be open-minded, tolerate opposing opinions;

- $\quad$ Thinking outside the box;

- Capacity for adaptation to different options arising and eventual evolution or changes of the activity itself;

- To promote abilities for the students to examine their own thinking, and that of others, about information that they receive through observation, experience, and formal research papers.

Self-awareness competency: the ability to reflect on one's own role in the local community and (global) society; to continually evaluate and further motivate one's actions; and to deal with one's feelings and desires.

- Probably one of the most innovative characteristics of this learning process, achieved by inciting and facilitating the self-management of the group so that the students themselves devised their own way of training, distributing the work, electing their representatives, etc.;

- Ability to put oneself in place of the other and start by applying the contents personally;

- Recognizing the role of each student's values, feelings, interests, abilities, and multiple identity facets when shaping one's thoughts and actions and, this, through sustained engagement over the months dedicated to prepare the debate with frequent meetings that helped them develop and express self-awareness; 
- Students were exposed to what they were competent in and what they could improve on the different seminars and meeting held during the preparation weeks.

Integrated problem-solving competency: the overarching ability to apply different problemsolving frameworks to complex sustainability problems and develop viable, inclusive, and equitable solution options that promote sustainable development, integrating the above mentioned competences;

- Multidisciplinary and interdisciplinary teams;

- Integrating problem analysis, AI, and Earth Observation techniques sustainability assessment, etc.;

- Play the stakeholder role or responsibility to assess effective sustainable solutions;

- Prepare joint argumentation and group reports.

\subsection{Organization and Scheduling}

To organize "The United Nations We Want" online event, a collaborative network was woven, following four steps (Figure 2). Firstly, the initial contact between the University and the Service for Geospatial, Information, and Telecommunications Technologies from the UN Support Base in Valencia was carried out in October 2019. One year later, in October 2020, an internal communication between the vice-chancellor for Equality, Diversity, and Sustainability and several deanships around the University was conducted. Thirdly, an internal communication in each of the faculties involved to designate faculty members committed with the project, generating very significant proposals from different faculties to participate in the event. In addition, finally, the student's representation from each faculty was selected by the faculty members.

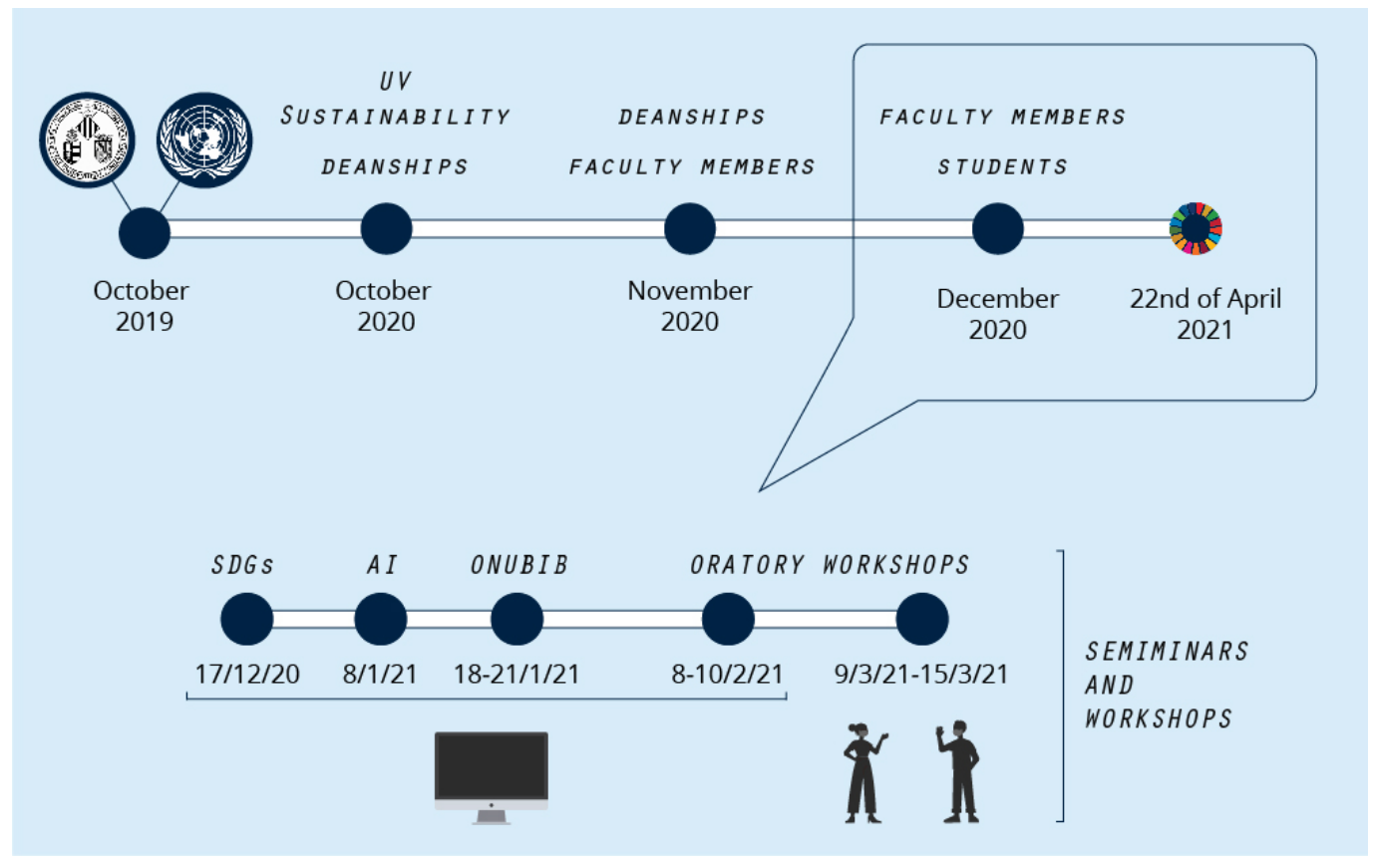

Figure 2. Organization steps followed. Source: own elaboration (vector face-to-face created from pikisuperstar's image in http:/ / www.freepik.es, accessed on 28 July 2019).

Whenever possible, in the faculties where several degrees are taught, this learning experience had to involve students and teachers from all of them, with the aim of achieving the greatest transversality. In addition, this would bring a greater diversity of points of view, thanks, precisely, to interdisciplinarity. Once the teamwork was composed, in December 2020, the second phase started. Thanks to the collaborative network created, big and small meetings were organized along the process. The first phase was common to all the working groups since it was focused on general meetings about how the different 
faculties (embodied by the students with the faculty members' support) could help to tackle the 2030 Agenda, combining AI and SDGs. Following the research and teaching interests of each faculty, linked to specific SDGs, four Discussion Panels or team works were created (see Table 2 and Figure 2):

Table 2. General distribution of faculties according to Discussion Panels. Tables by gender of Students (S) and Faculty members (F). Source: own elaboration.

\begin{tabular}{|c|c|c|c|c|c|c|c|c|c|c|c|c|c|c|c|c|c|c|}
\hline & \multirow{3}{*}{ Faculty } & \multicolumn{4}{|c|}{ Panel A } & \multicolumn{4}{|c|}{ Panel B } & \multicolumn{4}{|c|}{ Panel C } & \multicolumn{5}{|c|}{ Panel D } \\
\hline & & \multicolumn{2}{|c|}{$\mathrm{S}$} & \multicolumn{2}{|c|}{$\mathrm{F}$} & \multicolumn{2}{|c|}{ S } & \multicolumn{2}{|c|}{$\mathrm{F}$} & \multicolumn{2}{|c|}{ S } & \multicolumn{2}{|c|}{$\mathrm{F}$} & \multicolumn{2}{|c|}{$S$} & \multicolumn{3}{|c|}{$\mathrm{F}$} \\
\hline & & q & రె & 우 & & ㅇ & 0 & 우 & 0 & ㅇ & రం" & 요 & రె & & 0 & & & 0 \\
\hline$[\grave{Q} \approx]$ & Biology & 5 & 2 & & & & & & & & & & & & & & & \\
\hline [宅苍] & Chemistry & & & & & 1 & 2 & 1 & 1 & & & & & & & & & \\
\hline$[\grave{Q} \%]$ & Economics & & & & & & & & & 2 & 1 & 3 & 4 & & & & & \\
\hline$[\dot{\dot{\theta} \tilde{T}}]$ & Geography and History & & 2 & & 1 & & & & & 1 & 4 & 3 & & & & & & \\
\hline$\left[\hat{Q}^{\odot}\right]$ & Law & & & 2 & & & 2 & 2 & 1 & & 4 & & 2 & & 2 & & & 1 \\
\hline$[\grave{Q Q V} V]$ & Mathematical Sciences & & & & & 3 & 5 & & 1 & & & 1 & & & & & & \\
\hline$[\dot{Q} *]$ & Pharmacy & & & & & & & & & & & & & 1 & 1 & & & \\
\hline$[\hat{Q} ?]$ & $\begin{array}{l}\text { Philosophy and Educational } \\
\text { Sciences }\end{array}$ & & & & & & & & & 5 & 2 & 2 & & & & & & \\
\hline$\left[\hat{Q}^{\infty \infty}\right]$ & $\begin{array}{l}\text { Physical Activiy } \\
\text { and Sport Sciences }\end{array}$ & & & & & & & & & & & & & & 1 & & & \\
\hline$\left[\grave{\theta}_{-}\right]$ & Physics & 8 & 4 & 2 & 1 & & & & & & & & & & & & & \\
\hline$[\grave{O}: \because]$ & Physiotherapy & & & & & & & & & & & & & 1 & 1 & & & \\
\hline [Q母\% & School of Enginnering (ETSE) & 1 & 3 & 1 & 2 & 1 & 2 & & 1 & 1 & 3 & & & 1 & 3 & & & \\
\hline$[\grave{\hat{\theta}} \dot{\lambda}]$ & Medicine & & & & & & & & & & & & & & & & & \\
\hline$[\dot{\dot{\theta} \Psi}]$ & Psychology & & & & & & & & & & & & & & & & & \\
\hline$[\ddot{\theta} \ddot{\varphi}]$ & Social Sciences & & & & & & & & & 1 & & 2 & 1 & & & & & \\
\hline & TOTAL: 121 & 14 & 11 & 5 & 4 & 5 & 11 & 3 & 4 & 10 & 14 & 11 & 7 & 3 & 8 & & & 1 \\
\hline
\end{tabular}

The specific organization of each Panel will be explained in the following section. However, all of them followed approximately the same schedule of training, via diverse workshops and seminars, starting on 17 December 2020. These seminars tackled diverse subjects such as AI, access to digital resources (ONUBIB), and oratory public speaking techniques (Figure 2). Nevertheless, only five students from each Discussion Panel were able to attend the face-to-face oratory workshops, due to COVID-19 restrictions. These students were the ones who expressed their interest in being spokespersons on the debate Panels, 22 April 2021.

The selection of the two spokespersons of each panel was slightly different in each case (see specific cases in the following section). To ensure diversity, one had to be a man and the other a woman. However, in all the groups, the final decision was totally democratic, after attending the oratory workshops.

As we will see in Section 3, in all four of the Discussion Panels, two phases existed: a first one, led by the faculty members that allowed for having a first approach and putting together the steps to follow in each case; and a second phase, led by the students that was focused on the statements that they had to stand up for on 22 April. 


\section{Methodologies and Actions}

The workflows and actions undertaken by the four Discussion Panels were diverse. However, similar resources were used to organize the meetings, to work in pairs and groups, and to present the information compiled. Several technological resources were used to support and/or manage the remote collaboration. Some of them are widely known, like Microsoft Teams, Google Docs, Doodle, Miro, WhatsApp, and Discord, whereas others are less common or are versions of general tools, specifically tailored to be used in the University of Valencia, like Virtual Classroom on Moodle (See https: / moodle.com/ es / , Moodle, accessed on 28 July 2019 or Blackboard Collaborate ${ }^{\mathrm{TM}}$ (See https: / www. blackboard.com/, Blackboard Collaborate, accessed on 28 July 2019).

Besides these technological resources, students were provided with some basic materials, related to the SDGs and AI, for preparing the debate arguments. The main reference was the book "Inteligencia Artificial (IA) y Tecnologías Digitales para los ODS" [25]. This book analyzes and describes the state of the art on the use of artificial intelligence and digital technologies to address the 17 SDGs. It also presents an analysis of the weaknesses, threats, strengths, and opportunities for each SDG that allows for deriving a set of recommendations to promote the use of $\mathrm{AI}$ and digital technologies in the development of the 2030 Agenda. Additionally, students were also given some papers to complement this material, and they could even search for other materials by themselves at the UN library of the University. Reading these materials, before the meetings, helps the students prepare the arguments for the debate, but also leads them to interesting discussions during the meetings.

\subsection{Discussion Panels}

\subsubsection{Panel A}

Panel A was made up of 34 people coming from different areas of the University, 25 students (14 women and 11 men), and nine faculty members (five women and four men) (see Figure 2 and Table 2). The main topic of Panel A was focused on Science and Technology at the service of the SDGs and climate change mitigation. The SDGs implied, numbers $6,11,13,14$, and 15 , were related to water and sanitation, resilient and sustainable cities, climate action, and marine and terrestrial ecosystems. With the aim of training students on these SDGs and relating them to specific aspects of AI, it was decided that faculty members and students meet regularly two hours per week during six weeks. The structure of the meetings was as follows: in the first hour, a seminar was provided by a faculty member to train students on specific topics and highlight important issues related to the SDGs; the second hour was for discussing the seminar and SDGs closely related to it. To achieve this, the faculty member raised some questions during the meeting that led to fruitful discussions among students and faculty members, which pointed out important aspects that would aid to build the structure of the speech of debate. For preparing the seminar, students were provided with some previous material related to the SDGs and $\mathrm{AI}$, as we have referenced above. The following seminars were given by different faculty members each week. It is important to note that, due to COVID-19 restriction, all the seminars were online and also recorded.

- First seminar: it was thought to be convenient to dedicate one of the first training seminars to the synergistic action of AI and Earth Observation to driving and attaining the specific SDGs under consideration. This seminar was given by a faculty member of the Physics Faculty whose main area of research and expertise is Remote Sensing.

- Second seminar: The second seminar was aimed at explaining basic concepts like signal, sensor, distributed sensing, data digitization and their safe transmission and how these concepts are physically implemented (Internet of Things, smart sensorization, data aggregation, and verification through blockchain techniques). In addition, some aspects were discussed about privacy implications. This seminar was given by a faculty member of the School of Engineering. 
- Third seminar: A seminar on visual health cooperation was given by a faculty member of the Physics Faculty who has experience on this topic. She also showed significant personal volunteer actions carried out in low- and middle-income countries.

- Fourth seminar: This seminar was devoted to understanding the principle and actions to achieve a sustainable city, as well as learn about new movements such as slow cities. The goal is to achieve more sustainable and inclusive cities from a social, economic, and environmental point of view. This seminar was given by a faculty member of the Faculty of Geography and History.

- Fifth seminar: the main purpose of the seminar was to analyze the possibilities and risks of the use of AI from a legal perspective. This seminar was directly related to SDSs 6, 11, 13, 14, and 15.

- Sixth seminar: In this seminar, different subjects were explained around getting more women into science and engineering careers to achieve better science. This seminar was given by a faculty member of the Faculty of Physics who is an expert in gender equality.

As indicated earlier, the selection of the two spokespersons was a democratic decision. In the specific case of Panel A, a debate among candidates was made regarding the SDGs of this Panel. It was attended by faculty members and students. It was done online and people who could not attend were able to visualize it, as it was recorded. Afterwards, all members of this Panel voted to choose the two candidates. As pointed out before, through the discussion of the seminars and hard work of the students, a ten-minute initial speech was elaborated for the first part of the debate based on three points:

- How AI tools can be applied to the environment and the impact they may have.

- Data and its impact on environment and law issues implied.

- Training and education: raise the importance of education and training to achieve a more sustainable planet.

To reinforce the speech and data that supported it, a survey was carried out among students of the UV and other Spanish universities to search about the extent of their knowledge about the SDGs. The results concluded that $67 \%$ of the people who did the survey do not really know enough about the SDGs, and 30\% do not know anything about them at all. The survey also threw up that, in order to have a more sustainable planet, we should change our way of living instead of relying on technology.

The second part of the debate consisted in an argumentative situation where the two spokespersons of the desk would raise some questions to the spokeswoman of the UN who was a representative of the UN World Tourism Organization. To prepare for this part, all the members of the desk agreed to provide some arguments that follow a structure guided by a reasoning procedure and with data supporting them, as well as indicating the impact that his/her argument generated. A total of eight arguments were prepared. Some examples of them were:

- The increase of transport for tourism purposes leads to a substantial increase in $\mathrm{CO}_{2}$ emissions into the atmosphere.

- The technology, and in particular data exploitation and storage centers, increase water stress and greenhouse gas emissions, coming into conflict with local resources and the environment.

- Tourism is responsible for the majority of the residuals found in oceans.

- Tourism promotes the touristification of cities or certain neighborhoods, and with it the right of residents to access housing is violated (contemplated as goal in SDG 11), thus becoming unsustainable cities.

- A tourist at the Community of Valencia may spend four times more water than a common citizen, therefore breaking the water balance in one of the regions with most frequent droughts in Spain. 


\subsubsection{Panel B}

Panel B was composed of 16 students ( 5 women and 11 men) and 7 faculty members ( 3 women and 4 men): 22 people from four different faculties (see Figure 2 and Table 2). The topic of the debate in Panel B was "Artificial Intelligence in a finite planet: challenges of Agenda 2020". The work focused on some SDGs, in particular, 7 (Ensure access to affordable, reliable, sustainable, and modern energy for all), 8 (Promote sustained, inclusive, and sustainable economic growth, full and productive employment and decent work for all), 9 (Develop resilient infrastructure, promote inclusive and sustainable industrialization, and foster innovation), 10 (Reduce inequalities between and within countries) and 12 (Ensure sustainable consumption and production patterns).

In order to deepen the scope of each of these SDGs in relation to the theme of the Panel, it was decided to distribute the internal work by creating five groups, one per SDG, to address the evidence, deficits, and proposals of greatest interest and impact; and to share the results obtained weekly in the open for a joint and cooperative preparation of the debate. To this end, one day per week was set aside for a two-hour virtual meeting with all the members of the Panel, which contributed to collective enrichment by sharing the respective learning of each group and jointly addressing any doubts that arose. A spokesperson from each group reported on the progress made and the topics worked on, and then a collective debate was opened to reorient future lines of research. This way of proceeding allowed students to acquire skills and strengths they lacked, to be aware of the challenges posed by Agenda 2020 and to be able to better prepare for the final phase of speech drafting.

Since there were several issues of interest identified by the five groups, a total of ten, it was agreed to vote and reduce them to five themes, one per SDG, which turned out to be the following: technological and equal development for all countries: social, political, and economic inclusion; bad and good uses of AI; global access to affordable, reliable, and modern energy services; and more efficient consumption. All the conclusions reached by each group on these issues were compiled in a single document. This document was the basis for the final speech, the draft of which was prepared by the students selected by the students themselves for the public defense. The draft was made known to the members of the Panel, who made some observations that enriched the final text. Finally, the text underwent a series of adjustments in the light of the UN interlocutor with whom the Panel had to interact, all with the aim of maximizing the size of the subject, formulating the most appropriate proposals and setting out the challenges and deficits of $\mathrm{AI}$ on a finite planet in the light of the commitments made in the 2020 Agenda. Thus, the speech focused on three crucial topics related to AI:

1. Technological growth of businesses and the future of employment,

2. Data protection and privacy infringement,

3. Equal energy and technological development among countries.

Regarding the first, they asked what the UN was planning to prevent automation from generating a massive loss of employment and suggested that it should provide technical and economic assistance to promote the development of professional skills of those workers at risk from AI, especially in countries with a higher proportion of unskilled people.

Regarding the second, they wondered whether the violation of privacy is the price we have to pay to live in an advanced and globalized world and proposed as a way to protect data an International Convention for all countries, as exists in the European Union and, to this end, urge the UN to play an active and decisive role in bringing positions between the different States and pointing out and denouncing those that play the role of digital havens.

Finally, they were concerned to point out that there is no equitable distribution of resources for which the UN could help impoverished countries by providing them with technology they do not have and the trained human capital they need, and that it could help in building planning and in the development of renewable energies. It was proposed that the UN should ensure international cooperation and help to mitigate inequalities, encouraging the development of $R \& D$ through financial aid and promoting the transfer of new technologies to those countries with alarming poverty rates. 
The conclusion reached is that the key lies in making AI an instrument of globalization of rights and welfare and not of destabilization between countries and societies.

\subsubsection{Panel C}

Panel $C$ was made up of 42 people coming from 7 faculties, linked to diverse research areas of the University, 24 students (10 women and 14 men) and 18 faculty members (11 women and 7 men) (see Figure 2 and Table 2). As in other Discussion Panels, the collaboration networks allowed for working all together as well as in small groups. Internally, the meetings were organized in three levels: faculty, "group question", and Panel. The first meetings were focused on the proposal of several questions or subjects, related to the SDGs assigned to this panel: No Poverty (1), Zero Hunger (2), Quality Education (4), and Partnerships for the Goals (17).

During the months of January and February, the participants on Panel C worked by faculties to define which ones were the main interests and questions regarding these four SDGs. The main purpose of these meetings was to identify the most important problems, according to the students' interests, and to lay out how the UN could help to solve these main problems, using AI. As we have previously indicated, in order to prepare the arguments for the debate, students were provided with some basic material related to the SDGs and AI.

Once the four main questions and the students interested in each of them were selected, the work by "group question" started. All questions were focused on finding the problem, searching worldwide evidence, and giving solutions, keeping in mind the UN role. Those groups focused their debate on the following questions:

Question 1: What tools and creation of international alliances can the UN stimulate to promote cultural, social, and economic change that promotes well-being, the reduction of inequalities and justice in the digital age? (SDG 17)

Question 2: What are the social, psychological, economic, and ethical consequences of digitization in work and education? (SDG 4)

Question 3: How do AI and digitalized environments affect the environmental impact of capitalist production and consumption models? (SDGs 1 and 2)

Question 4: How can the great benefits of AI be used to solve poverty and fight the rejection of the poor (aporophobia)? (SDGs 1 and 2)

Given that, in the final debate with the UN, it was foreseen that two students from each Panel would be the interlocutors presenting the developed questions, it was necessary to choose among the participating students who would oversee this task. Since Panel C had four subgroups, it was determined that there would be at least one representative from each subgroup attending the oratory workshops and, finally, actively participating on 22 April (as a spokesperson or as supporters, giving data for answering back to the UN interlocutor after the initial speech).

During the month of March, weekly meetings were celebrated, at the same time that the general Discussion Panel work was progressing. These small meetings made the active participation of the students easier compared to the general virtual meetings. Throughout this process, the students had access to the large volume of books and specialized papers conserved at ONUBIB UV, which was crucial for addressing the questions, without excluding other sources of information.

Finally, in April, all of these ideas resulted in three main statements, showing the main problems, with specific evidence around the world and some solutions proposed. The creation of an ethics regulation to use Big Data and AI was highlighted. As students in Panel C expressed in their final speech, the correct use of AI can help to avoid digital divide, polarization of the inequality, and aporophobia, but it can also promote ethical management of natural resources, as well as the rationalization of production and consumption processes.

At the end, Panel $C$ resulted in two specific proposals. The first of these, and in order to reduce bad practices in the exploitation of natural resources, which put the planet and people at risk, students proposed the UN the creation of an International Social Commission 
for Public Denunciation or Accountability, which establishes minimum requirements to be included in the labor and industrial legislation of the countries, so that harmful exploitative practices gradually disappear.

In this same sense, and as the second proposal of Panel C, the UN might encourage sustainable production processes and fair trade, raising awareness of the need to use materials that do not harm the environment and the health of the people who inhabit it, as well as to future generations. In other words, encourage good practices around an economic model that priorities the dignity and well-being of the planet and people.

\subsubsection{Panel D}

A total of 20 people were involved in the development of Panel D work, 11 students ( 3 women and $8 \mathrm{men}$ ) and 11 faculty members (who were women with the exception of one man), all of them from different faculties and schools of the University (see Figure 2 and Table 2). The main focus of this Panel was the impact of AI on people and our human rights, which is why it was considered to address SDGs 3 (Good Health and Well-Being), 4 (Quality Education), 5 (Gender Equality), and 16 (Peace, Justice, and Strong Institutions).

Since it was intended that the students would actively participate in the search for the questions to ask the UN representatives, an attempt was always made to promote their involvement and responsibility. Students were encouraged to work autonomously, without faculty members' constant supervision, and collaboratively sharing knowledge between them, but always with the support of the faculty members. For that purpose, one meeting per week was planned to supervise and help students progress. Given the diversity of the SDGs to be covered, it was decided to split the group into two different subgroups (including students and faculty members), one addressing SDG 3 and another one addressing 4, 5, and 16 SDGs. In this way, the different sessions carried out, started with a common part of work with the whole group, and then the group was split to work on their objectives in a specific way. All of these meetings were held using the Teams platform (see Section 3).

The first sessions, performed along March, were dedicated to work on finding the questions to ask the UN representatives and to solve students' questions. In that sense, a seminar about the digital gender gap, gender biases in algorithms, and the impact of the lack of AI gender diversity in society was held.

Students were given access to the large volume of books and specialized papers conserved at ONUBIB UV, which was crucial for addressing the questions, without excluding other sources of information. Moreover, they were provided with different publications and materials on the SDGs to work on from where students could carry out their own search for information. The aim for the students was clear, not only about the questions to ask, but also about the scientific basis for asking them as well as to be able to reply to the possible answers and to maintain a serious and rigorous dialogue. After that process, the proposed questions were:

For SDG 3:

Question 1: How can AI benefit healthy living?

Question 2: We believe that the UN should lead the standard of healthy living with respect to different people, cultures, etc.

Question 3: How can AI support sanitary procedures, diagnosis, treatment, and surgery? For SDGs 4, 5, and 16:

Question 1: Is ethical and diversity training necessary to develop a human AI?

Question 2: What kind of training are AI professionals receiving about ethics and diversity?

Question 3: What kind of education do we receive about managing our data and privacy on the Internet?

Question 4: How could the UN regulate intervention, control, or define limits in AI? 
Given that in the final debate with the UN it was foreseen that two students from each Panel would be the interlocutors presenting the developed questions, it was necessary to choose among the participating students who would oversee this task. Since Panel D had two subgroups, it was determined that there would be one representative from each subgroup. The candidacies were intended to be free, so that students would decide which of them would be the representative. An open process was performed, using a poll, where students were able to indicate their interest in being the representatives of the Panel. After a negotiation process, three persons decided to take on this responsibility, adding one more person to the event just in case one of the first two suffered an unforeseen event.

The final speech was focused on some crucial topics related to the fact that AI and use of huge amounts of data are a fact, but the paramount issue is that people and institutions have the responsibility to guide it through human values. Students identify some of the controversies raised by $\mathrm{AI}$, and that, in a globalized world in which new technologies are here to stay, we need worldwide values to inspire their use. Students pose data concerning mental health problems and associated stigma, violence against women, occupational death data, and the COVID pandemic-among others, while acknowledging that the answer to revert these problems is not easy in any case, but they certainly believe that it should not be the normalization of inequalities, violence, or injustices.

To achieve that end, students propose the actualization of Human Rights to delimit the role that AI should occupy in the process of achieving the SDGs. They argued that, in the case of managing to achieve an optimal development of AI, while maintaining some source of inequality, we have failed. It would be a failure because the role of AI should be the contribution for the struggle to guarantee Human Rights and 2030 Agenda. They exposed the capacity of AI to break geographical barriers, improve the quality of life of people with disabilities, early detection of mental illness through behavioral analysis, prevent situations that could result in violence, facilitate the achievement of a global education, end illiteracy, understand the behavior of new viral strains, or prevent and monitor patients with chronic diseases—among others.

\section{Assessment of the Process of Participation}

The learning experience driven by faculty members and students, as well as wider stakeholders, played a critical role helping to shape new ways for educating for sustainability locating universities as engines of societal transformation [26]. The purpose of evaluating this strategy for mainstreaming the SDGs was to promote awareness among citizens on environmental and developmental issues overall, not to validate the results and conclusions of our example of good practice. In this sense, our purpose leads us to collect feed-back from participants after the finalization of the online event-which was as reported limited in its scale-in order to assess the learning experience. The collaborative project counted with the participation of the four thematic panels and the external agents who took part in the event. It was offered to a different number of participants who took part in the preparatory work and in the event itself: the UN interlocutors, the two 12 year-olds and the students and teachers linked to the specific Panels. Through the survey, information was collected from a representative number of participants, as shown below:

To assess the activity, a survey was prepared, and a sample was established for a 95\% confidence interval ( $5 \%$ significance level), as depicted in the last row of Table 3 . The survey included questions in four sections and was developed using Limesurvey ${ }^{(c)}$ software and distributed by e-mail to be completed online in about five minutes. The four sections included an assessment of programmatic aspects, process evaluation, evaluation of the results, and a general assessment of the project (see Additional Material for a full version). On 19 May 2021, the survey was sent to the participants and data were collected until 8 June with 112 people completing the answers. A total of 43 surveys were collected from faculty members, 67 from students, and five from collaborating members. Therefore, the marked samples have been complied with and the data are representative of the study universe. 
The assessment of the initiative carried out between UV and the UN is a fundamental and necessary element with which it is intended to know and evaluate the entire work process, training, and transfer between faculty members, students, and collaborating members. For this, each of the three groups involved have answered the survey, with similar questions to be able to compare from the three perspectives (students, faculty, and collaborators) their responses focused on three areas: tools used, knowledge, and general assessment.

Table 3. Participants in the survey and assessed sample.

\begin{tabular}{lrrrr}
\hline & Students & Faculty Members & Collaborators & Total \\
\hline Panel A & 25 & 9 & 1 & 35 \\
Panel B & 16 & 7 & 1 & 23 \\
Panel C & 24 & 18 & 1 & 46 \\
Panel D & 11 & 11 & 1 & 21 \\
Total & 76 & 45 & $4(+2)$ & 127 \\
Sample & 67 & 40 & 5 & 112 \\
\hline
\end{tabular}

In general terms, the three groups agree that the expectations they had in "The United Nations We Want" have mostly been fulfilled, although with differences (Figures 3-5). The collaborators are those who value this initiative between positive and very positive (80\%), followed by the faculty members (almost 70\%) and, lastly, the students who do not exceed half of the respondents. Therefore, the analysis with the lowest approval of expectations is that of the student group. This lower degree of compliance among students may be due to various reasons, on the one hand, because it may be different from what they had in mind and, on the other hand, a lack of experience in this type of activities and even a lack of communication and/or coordination. The union of all this could have been an intense process for the student, but where they have acted from a proactive, motivating, and enthusiastic dynamic.

Regarding the use of materials and tools for the proper development of the initiative, the three groups mostly approve this section. The use of the platform, available resources, and the involvement of the rest of the groups and coordination are highly valued; for students and faculty members, these elements have an approval that varies between $40 \%$ and $65 \%$ (Figures 3 and 4 ) — while, for external agents, it is much better valued and varies between $40 \%$ and $80 \%$ (Figure 5 ).

The work within the Discussion Panels has been interdisciplinary, and this has been highly valued by both faculty members (more than $85 \%$ value this action between positive and very positive) and students (more than 60\% value it as positive and very positive). It should be remembered that each Panel has had the participation of at least five faculties from different branches of knowledge. This has been one of the first initiatives in which both students and faculty members have worked in a transversal and interdisciplinary way, which can be considered a success.

Another important element of this assessment is the importance that the different elements have for the three groups, such as cultural and individual diversity, gender equality, social justice, environmental protection, and personal and professional development of both the student group and of the faculty members (Figures 3 and 5). In all of these items, there is a consensus on their importance. If we add the positive and very positive opinions, $80 \%$ of both groups think that they are very relevant; only cultural development and individual diversity have less importance for the students (almost 50\%).

In addition, the three groups agree to consider the expansion of knowledge on sustainable development, the SDGs, and other challenges as a very positive aspect. For collaborators and faculty members, this process has $85 \%$ and $80 \%$, respectively, positive and very positive assessment of knowledge and transmission of knowledge of the SDGs. In the case of students, most of them also think that this initiative has allowed them to improve their training (almost $80 \%$ ). This is a very important element, since this initiative has been 
a continuous process of training in very relevant concepts together with the SDGs, which are a basic element in the development of the 2030 horizon.

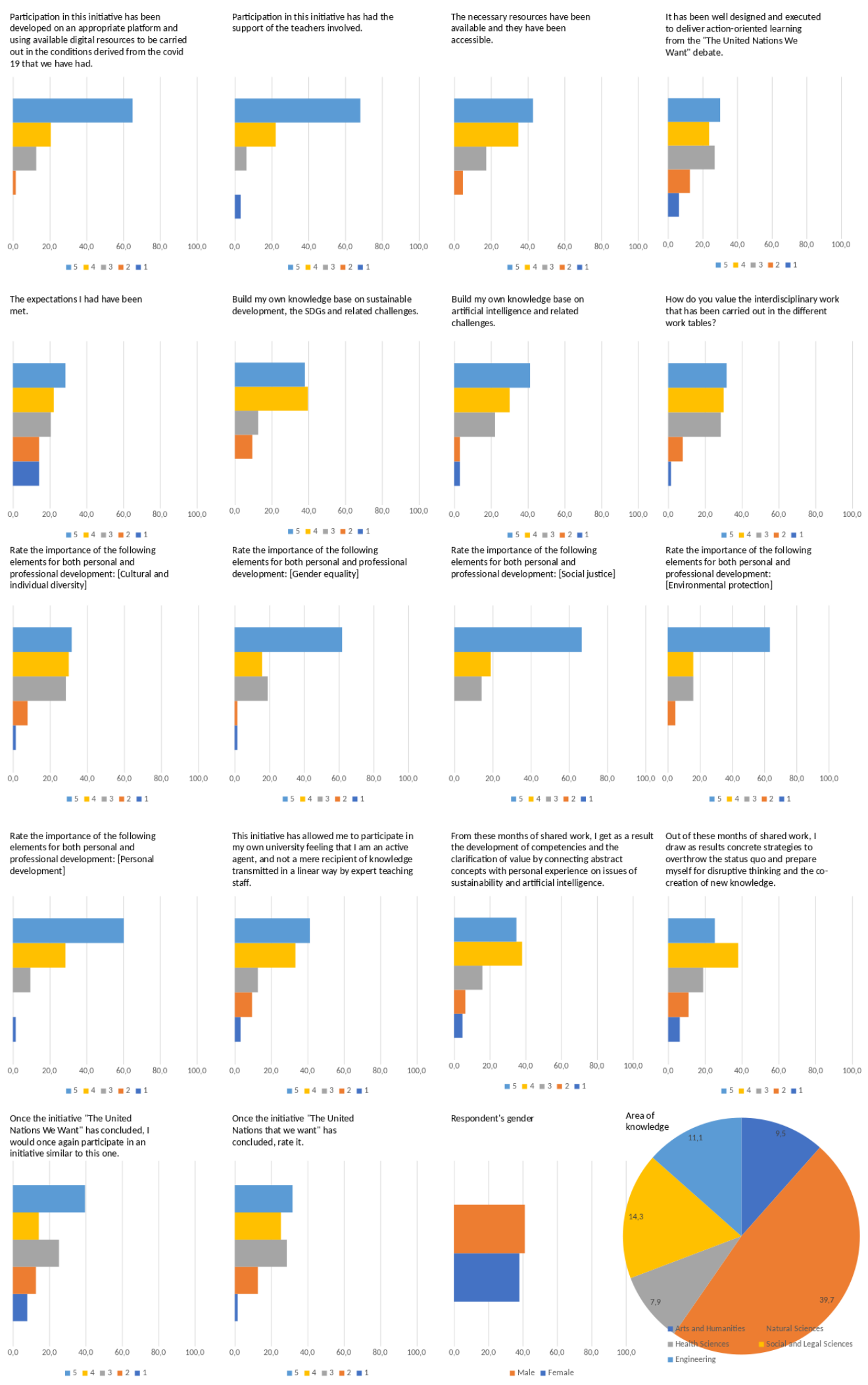

Figure 3. Question and answers of the survey proposed to the participant students. Bar lengths express proportions on the total sample size. 


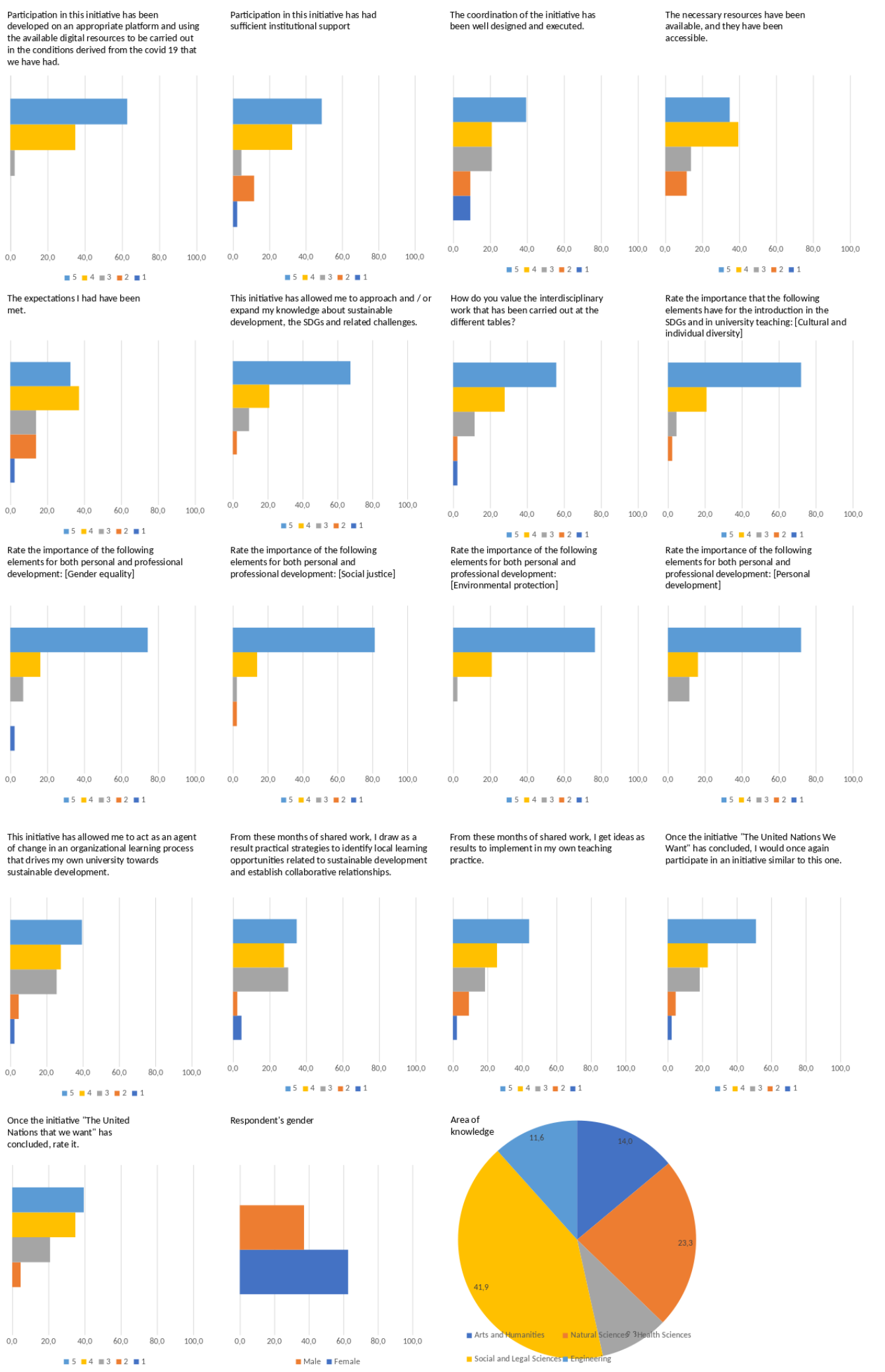

Figure 4. Question and answers of the survey proposed to the participant faculty members. Bar lengths express proportions on the total sample size. 


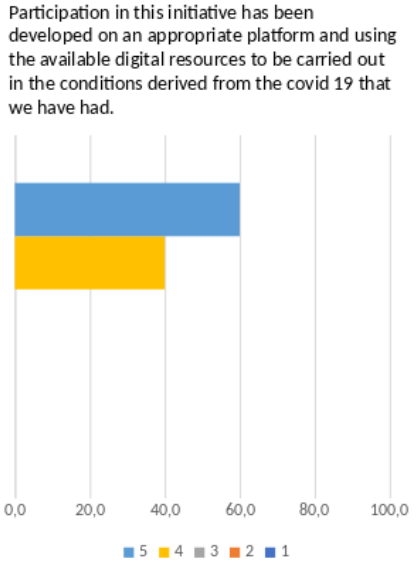

Participate in the event of the 75th anniversary of Participate in the event of the 75 th anniversary of not a mere recipient of a Transnational Agenda.

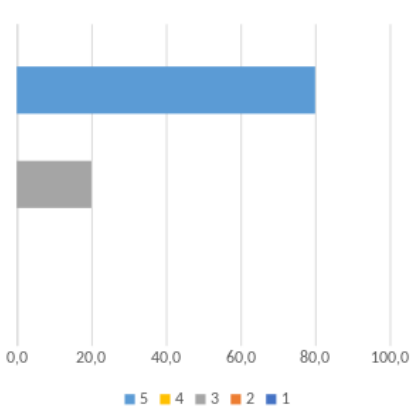

This initiative has allowed me to know the experience developed at the University of Valencia: how they apply the approach of Education for Sustainable Development and critical reflection on artificial intelligence and the SDGs.

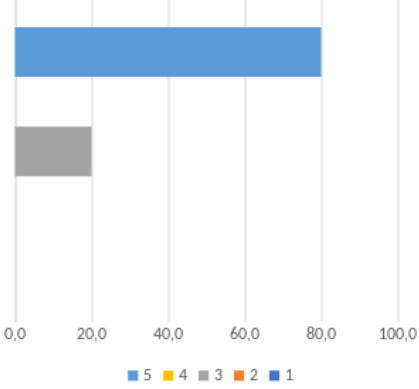

Participation in this initiative has had the request

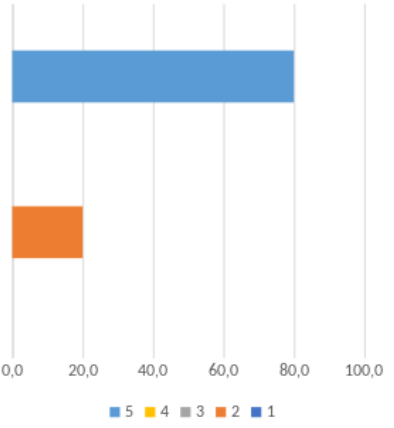

This initiative has allowed me to understand the results and analysis based on research on the positive and negative impacts that artificial positive and negative impacts that artificial
intelligence can have on the planet and on people.

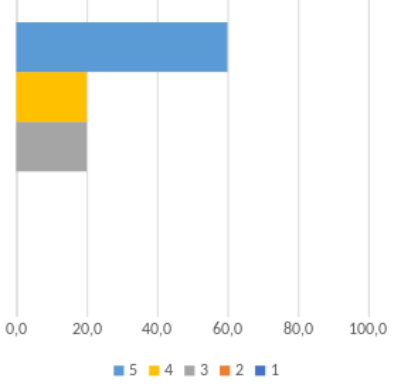

As a result of my direct participation in the event, I get as a result my visibility before the local community as an active agent for the transformation in favor of Sustainability and the 2030 Agenda.

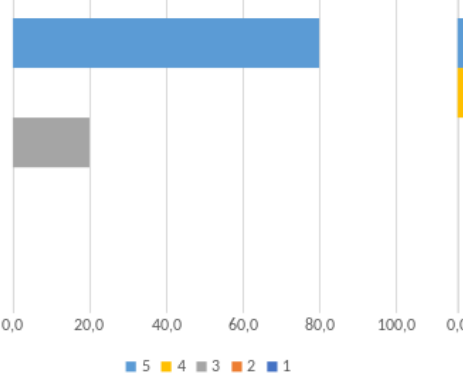

The necessary resources have been available, and they have been accessible.

The expectations I had have been

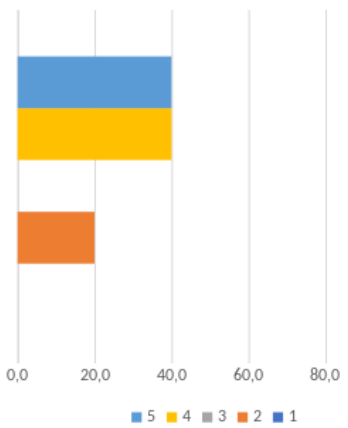

This initiative has allowed me to enrich $m y$ own knowledge base on sustainable development, the SDGs and related challenges.

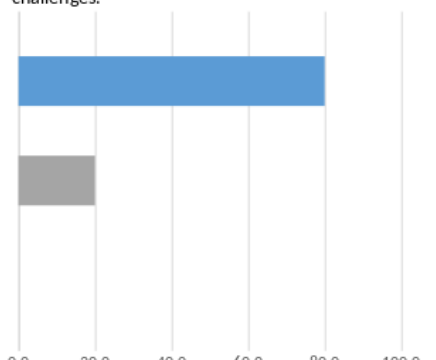

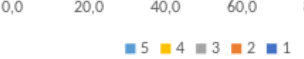

As a result of my direct participation in the event, I get the satisfaction of having participated in an initiative with the capacity to empower new generations and guide them towards environmental, social and economi sustainability.

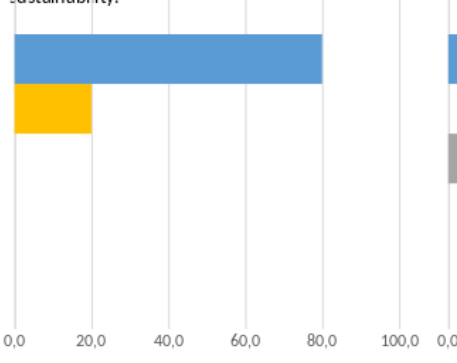

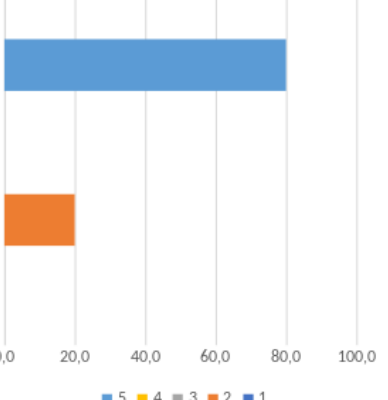

This initiative has allowed me to enrich my This initiative has all owed me to enrich my and related challenges.

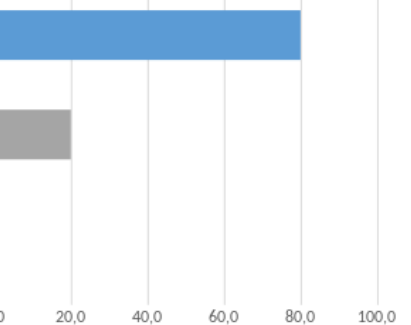

$$
=5=4=3=2=1
$$

Once the initiative "The United Nation that we want" has concluded, rate it

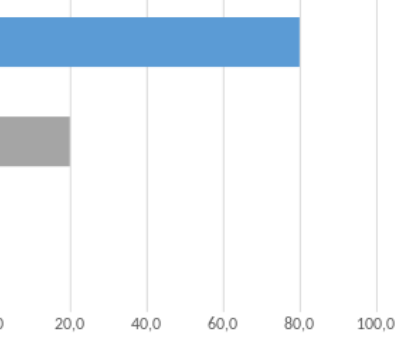

Figure 5. Question and answers of the survey proposed to the UN participant collaborators. Bar lengths express proportions on the total sample size.

Finally, the general assessment of this initiative has a majority approval of the three groups. The experience implemented by UV and UN obtains a very good rating among the groups of faculty members and collaborators with a valuation between positive and very positive in $78 \%$ and $80 \%$, respectively-while, in the case of students, this assessment drops to $45 \%$ of the participants. However, it should be noted that $25 \%$ of the students have an aseptic point of view of this process. Together with this assessment is the question of whether the three groups would participate in a similar initiative again, $80 \%$ of the collaborators said yes; for the faculty members, $75 \%$ would also be willing to do so, and, among the students, almost $55 \%$ would repeat, although almost $25 \%$ are indifferent to participate or not in another initiative. 


\section{Learning Results}

I. Addressing the challenges of Artificial Intelligence societies and technologies facilitated learning objectives for Education for SDGs.

Participation in the learning experience "The United Nations We Want" resulted in internalization of some of the specific learning objectives for education for SDGs outlined by [18]. The learning experience was designed taking into consideration the cross-cutting sustainability competencies. Individuals and societies around the world struggle to keep pace with the progress of AI, encountering many new challenges. A rapidly proliferating amount of data in a context that is increasing in complexity and uncertainty requires people that are capable of lifelong learning. As reported previously-through the assessment made by the surveys-approximately more than the $80 \%$ of participants felt confident to affirm seeing "the big picture" of the 2030 Agenda for Sustainable Development. In each of the four Discussion Panels, a selection of some specific SDGs occurred, but the cross-cutting ideas of sustainability were addressed in all Panels.

The learning experience reported in this article enabled participants to achieve the learning objectives for SDGs include cognitive, socio-emotional, and behavioral domains [18]. The cognitive domain comprises knowledge and thinking skills necessary to better understand the SDGs and the challenges in achieving it. The socio-emotional domain includes social skills that enable learners to collaborate, negotiate, and communicate to promote the SDGs as well as self-reflection skills, values, attitudes, and motivations that enable learners to develop themselves. The behavioral domain describes action competencies-which was not worked in an explicit manner in the learning experience "The United Nations We Want". This behavioral dimension of the learning objectives for all SDGs was encouraged to be achieved through other programs, such as the University Volunteer Program in UV Sostenibilitat. The learning experience "The United Nations We Want" allowed internal and external agents to address digital structural inequalities, by exposing people to the positive as well as negative possibilities of AI. As reported in other studies such as [27], p. 24: "The way we choose to develop and use $\mathrm{AI}$ is a choice that we as a society make. It has been long recognized that one fundamental way to achieve this is through Education". Young people, faculty members, and stakeholders were able to learn about what data and AI can be good for and what are the partial, often narrow, and general limitations of AI.

Participants had the opportunity to reflect about the SDGs agenda in a way that explicitly works from the inter-dependencies between and within the SDGs. It calls for the SDGs to be considered as an indivisible and integrated whole that should be addressed in a balanced way that accounts for interlinkages between the SDGs and between their social, environmental, and economic dimensions. Identifying negative interlinkages (or trade-offs) is important for ensuring that progress in one area does not lead to unexpected outcomes that undermine progress in other areas. On the other hand, positive interlinkages (or synergies) are useful for addressing multiple areas at once ([2], p. 40).

The collaborative work done between the UN and UV ensures that the contents of the debate are meaningful to all the participants, regardless of their background. Dialog with different perspectives and knowledge areas helped ensure that discussion questions make sense from the perspective of all participants. The co-creation processes favor shared knowledge to develop a high quality debate that promotes education for sustainable development. The aim of this online event was to encourage careful thinking, critical examination, a commitment to examining all sides, and to allow time for dialogue.

II. The dialogue between internal and external agents provoked high quality debate for understanding the artificial intelligence's challenges, opportunities, and interactions between the SDGs.

Around $80 \%$ of students who participate in "The United Nations We Want" reported that participating in the formative experience made most of them feel an active agent, not passive receptors of closed-knowledge. In a similar way, around $70 \%$ of faculty members reported in the survey that they saw themselves as change agents to drive their own 
university to Sustainability Development. Dialogue invites people to start imagining other scenarios and the real possibility of thinking critically about the current ones. It invites everyone to speak and open every position to criticism. Bringing people together to support transformative social agendas encourage people to rethink practices and imagine actions to develop such a transformative agenda. As Nel Noddings pointed out [28], when decentralized initiatives are coordinated and articulated and made meaningful, the people involved rise toward a better vision of themselves.

The United Nations Department of Economic and Social Affairs (UN DESA) along with the United Nations Institute for Training and Research (UNITAR) compiled the effects of valuable and effective participation in the dialogue on the 2030 Agenda: To improve self-esteem and earn the respect of others. To awaken a sense of belonging; to form part of a network in which they can talk of what they have experienced and feel the attention and support of others. To recover self-confidence, self-esteem and a feeling of autonomy to face questions that affect their community. To discover the potential and ability in them, along with a feeling of worth. To transmit strength and a feeling of solidarity; to be aware that they are not alone in their struggle against the same problems. To feel listened to and taken into account by those in power ([29], p. 34).

The formative experience "The United Nations We Want" highlighted how-through collaboration and support-a higher education institution can identify itself with sustainability by bringing together faculty members, students, and external institutional collaborations. The role of dedicated, interdisciplinary, and intra-organizational staff in addressing the knowledge-action gap in sustainability has been well presented by many authors [30-32].

Although, in some cases, faculty members may be more focused on their own career agenda and therefore not willing or able to dedicate time to new DE technology training [33], it may be reversed by involving people in a project that makes sense for them, as occurred in "The United Nations We Want". The participation of the different agents from inside and outside the University facilitate conversations, mutual learning, and partnerships between different sectors. On an internal level, it helped to identify areas of shared interest across the university and opportunities for internal collaboration. It made the engagement to build capacity of faculty members and students in the SDGs framework possible.

Higher education institutions all over the world are being implicated as both critical players and key stakeholders in engaging debate to address the growing number of sustainability challenges we face. It is paramount to avoid 'SDG-washing'. We are aware of 'Green-washing': the fact of using information to give the impression that a product, organization, policy, or project is environmentally friendly (even when it is not). The SDGs can be used in the same way. It is important to ensure that the information being reported is substantive and reliable and that the SDGs are not being used only to promote the perception that a university is contributing to sustainable development.

\section{Working with common horizons empowered youth and promoted necessary social impacts for sensitive responses.}

More than $60 \%$ of students who participate in "The United Nations We Want" reported that these four months of shared work, gave them concrete strategies to overthrow the status quo, and prepare themselves for disruptive thinking and the co-creation of new knowledge. On the other side of experience, around $70 \%$ of faculty members reported in the survey that they developed practical strategies to identify local learning opportunities related to sustainable development and established collaborative relationships. The learning experience empowered participants because it allowed them to engage as co-creators of proposals, viewed themselves as more skilled, and gave them some transferable skills.

Working in collaboration with stakeholders empowered participants and had social impacts not only on the broad audience, but on people. The online event "The United Nations We Want" was followed by nearly 160 nodes, including mass media agents, civil society entities, schools, and all-aged citizens in general. The event was covered by local newspapers, TV channels, social networks of the UV, and social influencers on 
Instagram. It also had an international impact on the Findery application which shares news, aggregating notes to Google Maps. They reported the activity done by United Nations Depository Libraries in support of the event. Making visible and empowering people is a great benefit to transformations for sustainability. Resilient, healthy, and flexible people are needed to reflect and design connections to new solutions and opportunities. People can make the change possible and contribute to their own well-being and their families and communities at large in our shared planet.

Bringing people together to focus on real-life problems and cultivating a sense of being responsible to them and for them is paramount. As presented by new feminist materialist scholars such as Donna Haraway, situating ourselves in a complex web of interdependent relations among human and more-than-human beings, can make the difference. Responsible pedagogy [34] is also ethic-political practices that incorporate a relational ontology and thus extend their transformative potential. In other words, responsible pedagogy constitutes relational processes through which social, political, and material entanglements are rendered capable of bringing social transformation.

Even scholars outside of the field of Education have argued for moving beyond a simple critique of the current direction of travel in data and AI practices, towards a more action-based approach that suggests practical ways forward to provide more socially responsible outcomes [35]. Supporters of this view recognize the challenges of local initiatives contributing to large-scale social change, particularly when the current networks of power and privilege are entrenched. Nevertheless, they view such an approach as important for change to occur. "The United Nations We Want" formative experience included the four overarching components that can support universities in their aim to embed Education for Sustainability [36]. These integrated components are: Inform the university community about sustainability; engage the different university stakeholders in the change process towards sustainability; empower individuals and groups to make change happen within their sphere of influence and action; and embed sustainability within existing university structures.

\section{Conclusions}

The strategy for mainstreaming the SDG among students and academic staff by performing the preparation of the online event "The United Nations We Want" has made the need to find mutual support and to create spaces for interdisciplinary dialogue and work clear. It was a relatively small-scale learning experience but a fruitful way of engaging students and faculty with SGD learning objectives and collaborative methodologies. The experience reported in this article allows us to assert that overcoming the sharp separation of the disciplines in higher education and emphasizing interdisciplinary approaches puts people in a better position to restore meaningfulness and to face today's challenges. Education for Sustainable Development can be enriched by interdisciplinary work and collaboration with stakeholders.

Clustering SDGs in four Panels to address social, economic, and environmental dimensions of sustainability was paramount in order to understand the interdependence among SDG in the 2030 Agenda. It helped to map appropriate preventive or corrective steps to ensure current and long-term sustainability within IA social and technological issues. Universities have the responsibility to create learning opportunities to wisely shape the perspective of ourselves and our relationships with our ecosystems in order for life on our planet to be possible. As stated at the beginning of this paper, how we relate with data and AI has and will have a profound impact on our identity as individuals and that of our institution, the University of Valencia. Academic rigor can help people and civilizations to focus on deep interactions and exchanges to pursue meaningful sense in removing inequality, injustice, and violence. 
Author Contributions: Conceptualization: V.V.-V.; software: J.D.; formal analysis: D.G.-E. and J.J.S.-L.; visualization: S.M.L., J.J.S.-L., D.G.-E. and S.R.; supervision: V.V.-V. and E.M.-G.; funding acquisition: E.M.-G.; writing—original draft, writing—review \& editing, validation, resources, project administration, methodology, investigation and data curation: all authors jointly. All authors have read and agreed to the published version of the manuscript.

Funding: “Claves de la Justicia Civil y Penal en la sociedad del miedo: feminización, inteligencia artificial, supranacionalidad, eficiencia y securitización", Prometeo GVA 2018/111, Valencian regional government. "Diseño operativo de la competencia «aprender a aprender» para los grados universitarios. Instrumentos de evaluación y propuestas para la enseñanza". Ministerio de Economía, Industria y Competitividad. EDU2017-83284-R, Spanish government. "SILKNOW. Silk Heritage in the Knowledge Society: from punched cards to big data, deep learning and visual/tangible simulations" European Union's Horizon 2020 research and innovation program under Grant No. 769504. "Roma Hispana: Inteligencia Artificial y Nuevas Tecnologías aplicadas al estudio, la musealización y la puesta en valor de Patrimonio Cultural español en Roma: la Spezeria di Santa Maria della Scala", AICO 2020/083, Valencian Regional Government.

Institutional Review Board Statement: Not applicable.

Informed Consent Statement: Not applicable.

Data Availability Statement: Not applicable.

Acknowledgments: Giovanna Ceglie, Director of the United Nations Global Service Centre, María Vicenta Mestre Escriva, Rector of Universitat de València and Joaquín Francisco Puig Ferrer. President of the Generalitat Valenciana for their participation and institutional support. Natalia Bayona, Director of Innovation, Education, and Investment of UNWTO; Yolanda Huerta, UPOV Legal Counsel and Director of Training and Assistance; Enrique Yeves Valero, 75th Anniversary Coordinator for Spain (and former Director of FAO in Spain) and Joaquín Nieto Sainz, Director of the ILO Office for Spain and Expert on Agenda 2030. Patricia Martínez Server, from the Center of Secondary Education Moli del Sol in Mislata and Pablo Manzanera Martínez, from the Center of Secondary Education Carles Salvador, Aldaia, the children who participated in the event. (The dissemination of their names have been explicitly authorized by their parents or legal guardians). Numerous students and members of the academic staff of the University of Valencia who were involved in the project, especially those who played the role of spokesperson of each panel: Fátima Della Bellver, Pablo Rosillo Rodes, Amina Abed, Lionel Vasseur Duvivier, Carlota Gómez Herrera, Javier Villarroya Villalba, Ana Suarez Rus, and Guzmán Blanco Saez.

Conflicts of Interest: The authors declare no conflict of interest.

\begin{tabular}{|c|c|}
\hline Abbrevia & ns \\
\hline The followi & g abbreviations are used in this manuscript: \\
\hline SDG & Sustainable Development Goals \\
\hline CEO & Chief Executive Officer \\
\hline $\mathrm{UN}$ & United Nations \\
\hline UV & University of Valencia \\
\hline AI & Artificial Intelligence \\
\hline UNTWO & United Nations World Tourism Organization \\
\hline UPOV & International Union for the Protection of New Varieties of Plants \\
\hline FAO & United Nations Organization for Food and Agriculture \\
\hline ILO & United Nations International Labour Organization \\
\hline ESD & Education for Sustainable Development \\
\hline ONUBIB & Deposit Library of UN at University of Valencia \\
\hline UNESCO & United Nations Organization for Science and Culture \\
\hline IESALC & UNESCO International Institute for Higher Education in Latin-American and Caribbean \\
\hline SGITT & UN Service for Geospatial, Information, and Telecommunications Technologies \\
\hline UN DESA & United Nations Department of Economic and Social Affairs \\
\hline UNITAR & United Nations Institute for Training and Research \\
\hline LMS & Learning Management System \\
\hline CMS & Content Management System \\
\hline
\end{tabular}




\section{References}

1. Harari, Y. Homo Deus: A Brief History of Tomorrow; Harper-Collins: New York, NY, USA, 2016.

2. Kestin, T.; van der Belt, M.; Denby, L.; Ross, K.; Thwaites, J.; Hawkes, M. Getting Started with the SDGs in Universities; Sustainable Development Solutions Network (SDSN): Melbourne, Australia, 2020.

3. Mochizuki, Y. Educating for Transforming Our World: Revisiting International Debates Surrounding Education for Sustainable Development. Curr. Issues Comp. Educ. 2016, 19, 109-125.

4. Miñano, R.; García Haro, M. Implementando la Agenda 2030 en la Universidad. Casos Inspiradores. In Technical Report, Red Española para el Desarrollo Sostenible (REDS); REDS: Madrid, Spain, 2020. Available online: https://reds-sdsn.es/wp-content/ uploads/2020/05/Dosier-REDS_Casos-ODS-Univ-2020_web.pdf (accessed on 28 July 2021).

5. Blanco-Portela, N.; Poza-Vilches, M.F.; Junyent-Pubill, M.; Collazo-Expósito, L.; Solís-Espallargas, C.E.A. Estrategia de investigación-acción participativa para el desarrollo profesional del profesorado universitario en educación para la sostenibilidad. Profr. Rev. Curric. Form. Profr. 2020, 24, 99-123.

6. Ferguson, T.; Roofe, C.G. SDG 4 in Higher Education: Challenges and Opportunities. Int. J. Sustain. High. Educ. 2020, 21, 959-975. [CrossRef]

7. Heleta, S.; Bagus, T. Sustainable Development Goals and Higher Education: Leaving Many Behind. High. Educ. Int. J. High. Educ. Res. 2021, 81, 163-177. [CrossRef]

8. Younie, S.; Audain, J.; Eloff, I.; Leask, M.; Procter, R.; Shelton, C. Mobilising Knowledge through Global Partnerships to Support Research-Informed Teaching: Five Models for Translational Research. J. Educ. Teach. Int. Res. Pedagog. 2018, 44, 574-589. [CrossRef]

9. Bautista-Cerro Ruiz, M.J.; Murga Menoyo, M.A.; Novo Villaverde, M. La educación ambiental en el siglo XXI (página en construcción, disculpen las molestias). Rev. Educ. Ambient. Sostenibilidad REAYS 2019, 1, 1103-1114.

10. Lafuente-Lechuga, M.; Cifuentes-Faura, J.; Faura-Martínez, U. Mathematics Applied to the Economy and Sustainable Development Goals: A Necessary Relationship of Dependence. Educ. Sci. 2020, 10, 339. [CrossRef]

11. Bekteshi, E.; Xhaferi, B. Learning about Sustainable Development Goals through English Language Teaching. Res. Soc. Sci. Technol. 2020, 5, 78-94. [CrossRef]

12. Petillion, R.J.; Freeman, T.K.; McNeill, W.S. United Nations Sustainable Development Goals as a Thematic Framework for an Introductory Chemistry Curriculum. J. Chem. Educ. 2019, 96, 2845-2851. [CrossRef]

13. McCunn, L.J.; Bjornson, A.; Alexander, D. Teaching Sustainability across Curricula: Understanding Faculty Perspectives at Vancouver Island University. Curric. J. 2020, 31, 557-572. [CrossRef]

14. Maina-Okori, N.; Koushik, J.R.; Wilson, A. Reimagining Intersectionality in Environmental and Sustainability Education: A Critical Literature Review. J. Environ. Educ. 2018, 49, 286-296. [CrossRef]

15. Limón Domínguez, D.; Solís Espallargas, C. Educación Ambiental y enfoque de género, claves para su integración. Investig. Esc. 2014, 83, 37-50. [CrossRef]

16. Arevalo, J.A. Gendering sustainability in management education: Research and pedagogy as space for critical engagement. J. Manag. Educ. 2020, 44, 852-886. [CrossRef]

17. Meadows, D.; Perelman, L. Limits to Growth, a Challenge to Higher Education. Prospect. Q. Rev. Educ. 1977, 7, 33-43. [CrossRef]

18. United Nations Organization for Education and Culture (UNESCO). Education for Sustainable Development Goals. Learning Objectives. 2017. Available online: https://www.unesco.de/sites/default/files/2018-08/unesco_education_for_sustainable_ development_goals.pdf (accessed on 28 May 2021).

19. Russell, S.; Norvig, P. Artificial Intelligence: A Modern Approach, eBook, Global Edition; Pearson Education: London, UK, 2016.

20. Bishop, C.M. Pattern Recognition and Machine Learning; Springer: New York, NY, USA, 2007.

21. Hinton, G.H.; Vinyals, O.; Dean, J. Distilling the Knowledge in a Neural Network. NIPS Deep Learning and Representation Learning Workshop. 2015. Available online: http:/ / arxiv.org/abs/1503.02531 (accessed on 28 July 2021).

22. Sintov, N.; Kar, D.; Nguyen, T.; Fang, F.; Hoffman, K.; Lyet, A.; Tambe, M. Keeping It Real: Using Real-World Problems to Teach AI to Diverse Audiences. AI Mag. 2017, 38, 35-47. [CrossRef]

23. Ramos Torres, D.I. Contribution of higher education to the Sustainable Development Goals from teaching. Rev. Española Educ. Comp. 2021, 37, 89-110. [CrossRef]

24. Vázquez-Verdera, V.; Portillo Poblador, N. La competencia aprender a aprender en el marco de las competencias transversales clave para avanzar en los ODS en las universidades. In Aprender a Aprender, Competencia Clave en la Sociedad del Conocimiento. Su Aprendizaje y Enseñanza en la Universidad; Gargallo-López, B., Pérez-Pérez, C.C., Eds.; Tirant lo Blanch: Valencia, Spain, 2021.

25. Montes, R.; Melero, F.; Palomares, I. Inteligencia Artificial y Tecnologías Digitalespara los ODS; Real Academia de Ingeniería: Madrid, Spain, 2021.

26. Geli de Ciurana, A.; Collazo Expósito, L.; Mulà Pons de Vall, I. Contexto y evolución de la sostenibilidad en el currículum de la universidad española. Rev. Educ. Ambient. Sostenibilidad REAYS 2019, 1, 1102. [CrossRef]

27. Winters, N.; Eynon, R.; Geniets, A.; Robson, J.; Kahn, K. Can We Avoid Digital Structural Violence in Future Learning Systems? Learn. Media Technol. 2020, 45, 17-30. [CrossRef]

28. Noddings, N. Starting at Home: Caring and Social Policy; University of California Press: Berkeley, CA, USA, 2002. 
29. Williams, L.; Tahtinen, L.; Costa, N.; Karst, L.; Proden, E. Participación de Actores en la Agenda 2030 Para el Desarrollo Sostenible. Guía Práctica. (In Spanish). 2020. Available online: https://www.miteco.gob.es/es/ceneam/recursos/pag-web/actores-agenda2 030-dllo-sostenible.aspx (accessed on 28 July 2021).

30. Warr Pedersen, K.; Pharo, E.; Peterson, C.; Clark, G.A. Wheels of Change in Higher Education: A Collaborative, Multi-Stakeholder Project as a Vehicle for Sustainability Education. Int. J. Sustain. High. Educ. 2017, 18, 171-184. [CrossRef]

31. Courtenay-Hall, P.; Rogers, L. Gaps in Mind: Problems in Environmental Knowledge-Behaviour Modelling Research. Environ. Educ. Res. 2002, 8, 283-297. [CrossRef]

32. O'Brien, K. Global environmental change III: Closing the gap between knowledge and action. Prog. Hum. Geogr. 2013, 37, 587-596. [CrossRef]

33. Angolia, M.G.; Pagliari, L.R. Factors for Successful Evolution and Sustainability of Quality Distance Education. Online J. Distance Learn. Adm. 2016, 19.

34. Bozalek, V.; Zembylas, M. Towards a Response-able Pedagogy across Higher Education Institutions in Post-Apartheid South Africa: An Ethico-Political Analysis. Educ. Chang. 2017, 21, 62-85. [CrossRef]

35. Daly, A.; Devitt, S.; Mann, M.E. (Eds.) Good Data, Theory on Demand; Institute of Network Cultures: Amsterdam, The Netherlands, 2019.

36. Cebrián, G. The I3E Model for Embedding Education for Sustainability within Higher Education Institutions. Environ. Educ. Res. 2018, 24, 153-171. [CrossRef] 